\title{
CONDIÇÕES DE PRODUÇÃO DE SENTIDOS EM TEXTOS DIDÁTICOS ${ }^{1}$ \\ (Conditions of Senses Productions in Didatic Texts)
}

\author{
Suzani Cassiani de Souza ${ }^{2}$
}

\section{RESUMO}

O trabalho discute o uso de textos numa escola de jovens e adultos, com um sistema de ensino individualizado localizado no interior do estado de São Paulo, na disciplina de ciências. Tomando como referência a análise do discurso da escola francesa, o trabalho enfatiza como alguns aspectos, considerados negativos pelos professores, puderam detonar propostas de mudanças, visando a melhoria do ensino naquela escola. Dentre esses aspectos negativos, cito a precariedade do material didático, atravessado pelo silêncio que foi imposto pelo político na época da ditadura. Também levanto a questão de que este mesmo material didático tão criticado pelos professores, pôde levar os estudantes à leituras e interpretações inesperadas, levando-nos a supor que as leituras dependem muito mais da interação entre os sujeitos e os textos, do que necessariamente do dizer do autor.

Palavras Chaves: ensino de ciências, análise do discurso, educação de jovens e adultos

\section{ABSTRACT}

This research discuss the use of texts in science education, in a adult education school located in the State of São Paulo. Taking as reference the discourse analysis of the French school, the research emphasizes how aspects known as negatives ones by the teachers, got to beginning changing ideas, aiming for the education improvement in that school. Between all this negative aspect, I point the precariousness of didactic materials, passed by the silence which was imposed by politics in those dictatorship' days. I also bring up in discussion the idea that same didactic materials, which are always criticized by teachers, can take students to unexpected readings and interpretations, taking us to assume how the reading depend much more the interaction between individual and texts, that the speech of the author.

Key Words: science education, discourse analysis, adult education

\footnotetext{
${ }^{1}$ Apoio $\mathrm{CNPq}$

${ }^{2}$ Depto. Metodologia de Ensino Centro de Ciências da Educação - Universidade Federal de Santa Catarina scsouza@ced.ufsc.br
} 


\section{INTRODUÇÃO}

A função básica da educação de jovens e adultos no Brasil é suprir a escolaridade de adultos e adolescentes acima de 14 anos, que por várias razões, entre elas a necessidade de trabalhar, não puderam concluir seus estudos na idade convencionada como correta. Essa função demonstra claramente a desigualdade social presente no Brasil, uma vez que para cidadãos de um mesmo país, tipos de ensino diferentes são oferecidos, diferenciando provavelmente o saber escolar. Mesmo reconhecendo os equívocos de natureza social que o instituíram admitimos as possíveis contribuições desse tipo de ensino para os trabalhadores e percebemos que um trabalho pedagógico mais sério e crítico pode ser realizado, visando o acesso real do aluno ao saber escolar.

$\mathrm{Na}$ abordagem da educação de jovens e adultos fazemos um recorte enfatizando a "escola aberta", cuja característica principal é o ensino individualizado. No estado de São Paulo, desde 1981, recebeu a denominação de Centros Estaduais de Ensino Supletivo (CEES) e o nosso enfoque será para um dos 20 existentes, que atualmente funciona em espaço cedido pela Universidade Estadual de Campinas.

O CEES-Unicamp, como é comumente chamado, é destinado a funcionários da universidade, mas a maioria dos alunos é de trabalhadores da região de CampinasSP. O ensino é individualizado possibilitando a flexibilidade de horários, principalmente aos alunos trabalhadores de turnos.

Apesar deste aspecto relativo à flexibilidade ser extremamente importante para o acesso do aluno à escola, enquanto professora dessa escola considerava o ensino individualizado muito aquém de seus objetivos. Tínhamos preconceito deste tipo de ensino, tanto em relação à sua origem que considerava comportamentalista, como pela ideologia transmitida aos alunos, pois esses centros haviam sido criados durante a época da ditadura militar, provavelmente para abafar movimentos populares de educação durante a década de 60 . Segundo depoimento de Germano (1983)

"com o advento do movimento militar, vários integrantes da Campanha De Pé no Chão em Natal (RN) foram presos, exilados ou simplesmente desapareceram, sendo apreendidos e destruídos os materiais didáticos produzidos e as escolinhas com telhados de sapé construídas durante a Campanha, segundo justificativa dos militares, 
por motivos de: "restaurar a ordem e a tranqüilidade para o bem da Pátria" (p. 14)

Coincidência ou não, a cidade escolhida para a implantação do primeiro Centro de Ensino Supletivo (CES) foi Natal, talvez com o intuito de "substituir" um dos mais bonitos movimentos populares que ali aconteceu. Este CES foi um dos únicos do país, que recebeu materiais e instalações tão boas, quanto previa o modelo norte-americano, no qual havia sido inspirado.

No estado de São Paulo, o primeiro CEES foi implantado em 1978 e o seu material didático se diferenciava dos outros estados, pois uma das exigências da Secretaria de Educação do Estado para a implantação do programa era a elaboração do seu próprio material didático.

Em 1987, o CEES-Unicamp iniciou suas atividades e a equipe de ciências propôs mudanças de caráter estrutural na escola como a reformulação de provas, inclusão de textos e aulas grupais de laboratório, disposta a buscar elementos que permitissem refletir sobre o ensino possível nessa escola, com a pretensão de melhorar a qualidade de ensino, contribuir para a diminuição da evasão de alunos e superar a característica comportamentalista dos módulos adotados.

Essas mudanças provocadas visaram quebrar a rotina de um curso, que originalmente tinha como proposta fazer com que os alunos estudassem individualmente módulos de ensino programado, a aplicação de provas e explicação de eventuais dúvidas pelos professores, quando procurados pelos alunos.

Como ainda restavam dúvidas sobre o significado dessas mudanças e sobre os resultados alcançados, realizamos uma reflexão teórica mais aprofundada investigando a dinâmica das relações aluno/professor e aluno/material didático, sendo grande parte do esforço voltado para o (re)conhecimento de concepções e ações dos professores e das interações ocorridas nessa escola (SOUZA, 1995). Especificamente, neste trabalho discuto o uso de textos nessa escola supletiva, na disciplina de ciências, tomando como referência a análise do discurso da escola francesa. O trabalho enfatiza como alguns aspectos considerados negativos pelos professores, puderam detonar propostas de mudanças, visando a melhoria do ensino naquela escola. Dentre esses aspectos negativos, cito a precariedade do material didático, atravessado pelo silêncio que foi imposto pelo político naquela época da ditadura. Também levanto a questão de que este mesmo material didático 
tão criticado pelos professores, pode levar os estudantes à leituras e interpretações inesperadas, levando-nos a supor como as leituras dependem muito mais da interação entre os sujeitos e os textos, do que a escritura impressa.

\section{AS CONDIÇÕES DE PRODUÇÃO, A FORMA E O CONTEÚDO DO MATERIAL DIDÁTICO}

Neste trabalho faremos um recorte, para tentar explicitar o trabalho com os módulos, através de uma análise baseada nos referenciais da Análise de Discurso conforme nos aponta Pecheux (1990, 1993) e Orlandi (1993, 1996, 1995a, 1995b).

Como já foi dito anteriormente, os módulos foram escritos na década de 70 , quando ainda estava em vigor a ditadura militar. Um dos autores dos módulos de ciências, que escreveu a parte de biologia, relatou em entrevista a influência da censura e da auto-censura quando estes foram escritos. Esse autor possuía na época um cargo administrativo na Secretaria de Educação, mas devido à falta de professores de biologia, cuja área era sua formação de origem, elaborou os módulos de ciências juntamente com os professores de química e física.

Além disso, ele acompanhou todo o processo de montagem do curso no estado de São Paulo, e afirmou que a escolha da metodologia dos CEES, veio do Ministério da Educação e Cultura e "tinha uma fundamentação psicológica fortemente skinneriana, um sistema bem comportamentalista". Para o trabalho de confecção dos módulos o MEC sugeriu uma leitura baseada em T. Nagel et.al $(1974)^{3}$.

Certamente, o vínculo teórico dos módulos usados no CEES-Unicamp vem do behaviorismo norte-americano, fundamentado nas idéias de B.F.Skinner, cujas pressuposições sustentam que só fatos observáveis e medidos merecem ser trabalhados. Nos módulos baseados essencialmente em objetivos comportamentais que indicam uma desejada mudança de comportamento, é dada prioridade à definição de conceitos e são privilegiadas ações que podem ser observadas e medidas nos alunos. Na elaboração desses objetivos, de acordo com a teoria comportamentalista, verbos como compreender ou entender, não são usados, pois

\footnotetext{
${ }^{3}$ Nesse livro pode-se ter uma idéia da produção de materiais pelo sistema comportamentalista. É um manual sobre o ensino individualizado, onde se fazem observações de como se deve elaborar objetivos bem definidos e comunicá-los abertamente aos alunos. Nas avaliações existe, entre outras coisas, uma sugestão de se abolir notas e séries e também uma discussão sobre o tempo que deve ser dado ao aluno para as atividades conforme suas necessidades.
} 
não podem ser observados. Verbos como citar, demonstrar, indicar, reconhecer são amplamente utilizados. Porém, apesar de sua origem comportamentalista e sua ênfase nos objetivos, os textos fogem pouco do usual, estando sujeitos às mesmas críticas que comumente se fazem aos livros didáticos: conteúdos nem sempre relevantes para os estudantes, geralmente fragmentados e apresentados de forma bastante abstrata (SOUZA, 1995).

Ao se dar ênfase a definições e classificações, como por exemplo, "quais são as partes de uma flor", e não considerarem as funções e o seu funcionamento, deixa-se de lado conteúdos quase sempre mais relevantes. As respostas fechadas presentes nos exercícios e conseqüentemente nas provas podem dar aparência de facilidade e daí decorrer maior segurança ao aluno. Normalmente o apelo é para a memorização.

Um outro exemplo que os módulos comportam é quando os alunos aprendem as funções dos sistemas que formam o corpo humano. Normalmente não fica a idéia de que os sistemas são interligados, ou seja, o aparelho respiratório serve para trocar o gás carbônico pelo oxigênio, que será levado pelo aparelho circulatório, através do sangue impulsionado pelo coração, até as mitocôndrias das células. Não abordando o tema na forma de processo, geralmente o aluno fica com a idéia de que os sistemas têm funções distintas e não se relacionam.

Além dessas, muitas são as dúvidas sobre os textos utilizados nesse ensino individualizado tanto na forma apresentada como nos conteúdos existentes nos módulos. Apesar de sua precariedade, os alunos interagem com os textos de diversas formas como iremos mostrar nesse exemplo abaixo. Muitas vezes eles trazem questões relevantes que demonstram avanços na interação com o conhecimento e na sua forma de se relacionar com o texto. Neste caso, uma aluna estudava um módulo sobre o conteúdo relativo ao Ar, surgiram dúvidas desse tipo, as quais ela trouxe por escrito:

"1 - Foram construídos dois hemisférios de meio metro de diâmetro, adaptados um ao outro, eles formaram uma esfera oca, perfeitamente fechada, juntou os hemisférios de extraiu o ar da esfera. Como esse ar foi extraído?

2 - Se a pressão atmosférica foi demonstrada pela primeira vez em 1854 por Otto Von Guericke, como o barômetro aparelho usado para medir o mesmo foi construído em 1643, por Torricelli? 
3 - Como interpretar expressões como $1 \mathrm{~cm} / \mathrm{Hg}$ ?

4 - O que são: sifão, pipetas, altímetros?"(SOUZA, 1995, p 103).

Esses dados, provenientes de uma pesquisa de natureza etnográfica, mostraram a imprevisibilidade das leituras. Como se pode perceber, a aluna levantou dúvidas variadas em relação a informações incompletas presentes nos módulos, como, por exemplo, na questão quatro quando ela questiona o significado de algumas palavras presentes no texto, além de apontar uma aparente contradição na questão dois.

Esse e outros exemplos observados nos demonstram que os alunos, durante a leitura dos módulos, apresentam inúmeras idéias sobre os assuntos. Expectativas são geradas, dúvidas e curiosidades são levantadas, preconceitos e conceitos são ou já estão formados, enfim diversas são as formas de olhar o mesmo conteúdo. Ficamos surpresos enquanto professores, quando ouvimos de vários alunos "Parece que os módulos conversam com a gente, deixa tudo explicado é gostoso de ler". Apesar de todas críticas levantadas era preciso investigar as relações dos alunos com a leitura.

\section{ANÁLISE DE UM TEXTO DOS MÓDULOS DE CIÊNCIAS}

Segundo Orlandi (1996) o texto tem suas relações com outros já existentes possíveis e imaginários por isso é incompleto, além de suas relações com as condições de produção, os sujeitos e a situação. De certa forma, já contextualizamos essas relações, e então neste momento buscaremos entrar um pouco mais a fundo no texto, propriamente dito.

A tarefa do analista do discurso é "compreender, ou seja, explicitar os processos de significação que trabalham o texto: compreender como 0 texto produz sentidos, através de seus mecanismos de funcionamento." (ORLANDI, 1996, p.88)

Para nós, um dos textos mais significativos nesse contexto é o que se refere à Doença de Chagas (em anexo), pois ele alertou a equipe de ciências em 1987, para as mudanças urgentes que precisavam ocorrer. Ele se encontra no módulo de número seis, que enfatiza a existência de protozoários que causam algumas doenças. Normalmente os textos são elaborados pelos autores dos módulos, mas 
nesse caso é extraído do livro "Saúde-Programa 1" de Paulo Maurício Silva e S. R. Fontinha Filho, o que nos levar a supor um certo jogo de responsabilidades acerca de um assunto polêmico, como veremos mais adiante.

O texto consta de cinco parágrafos, sendo que o primeiro trata do descobridor da doença de Chagas, indicando a origem do nome. Geralmente quando se trata da história da ciência, o módulo traz informações incompletas e superficiais. Baseado somente em datas e nomes, essa história encontrada nos módulos é aquela em que são frisadas algumas descobertas por cérebros iluminados, forma muito parecida com a que encontramos em outros manuais didáticos.

O segundo e o terceiro relata como a doença é transmitida; o quarto e quinto coloca formas de se evitar a doença. Esse texto no módulo está escrito em itálico, com excecão de algumas palavras: "transmitida por um percevejo; barbeiro; protozoário denominado Trypanosoma cruzi (grifo nosso); causador da doença de Chagas; combater o barbeiro que é o seu transmissor". Essas palavras destacadas parecem denotar uma certa importância para o autor do módulo que transcreveu o texto, pois um dos objetivos deste módulo é "Identificar os causadores e transmissores da doença de chagas". Esse fato demonstra claramente que as palavras foram destacadas pelo autor do módulo e não pelo autor do texto.

Apesar da linguagem utilizada no módulo ser informal, por exemplo, "copie em seu caderno, responda as questões, se acertou todas as questões prossiga, faça agora os exercícios" no texto citado ela aparece de forma impessoal, ocultando provavelmente uma caracterização histórica e social do autor. Em se deve, se torna, atinge, passa pode representar a suposta neutralidade do discurso científico, sem nenhuma intervenção humana. É como se mundo falasse dele mesmo, o sujeito se apaga, está ausente (Authier, 1982).

De uma forma geral o grande silêncio que aparece aqui é o maior motivo da existência da doença - o fato de milhões de brasileiros pobres morarem em casas de pau-a-pique, cuja precariedade propicia o alojamento de barbeiros, transmissores da doença. Há duas referências no texto quanto a este fato:

A) Durante o dia, os barbeiros se escondem nas frestas das portas e das paredes ou na palha no telhado de casebres.

B) O melhor meio de se evitar a doença de Chagas é combater o barbeiro seu transmissor. O combate é feito com um inseticida chamado BHC. Outra forma 
eficiente é a construção de casas, com paredes de tijolos e argamassa, portas sem frestas e cobertura de telhas (grifos do autor).

Em A) pode-se observar que o texto não discute o motivo das pessoas morarem nesses locais. A direção argumentativa do texto é sempre colocada como uma condição natural do indivíduo.

$\mathrm{Na}$ segunda citação (B) prioriza-se como medida mais eficiente (o melhor meio de se evitar) a utilização de um veneno, por sinal proibido em vários países por causa de sua toxicidade (inclusive no Brasil, esta informação do módulo está desatualizada), e em segundo plano - outra forma eficiente - a construção de casas de alvenaria, mais uma vez não colocando as condições desiguais da população. Nota-se a ênfase na primeira alternativa, onde não é colocado como um dos melhores meios,mas sim o melhor meio. Nesse sentido, aparentemente encontra-se uma contradição: a segunda medida seria a solução, pois a situação atual é a causa da doença, no entanto ela é colocada como uma medida secundária, pois falar da pobreza poderia significar demonstrar um descontentamento com o governo militar, o que por sua vez poderia resultar em represálias.

Ainda no terceiro parágrafo, em a pessoa picada, ao se coçar, facilita a entrada do protozoário, dá a impressão novamente de que a contaminação da doença depende do indivíduo e não das condições em que vive.

No último parágrafo, quando o texto se remete a o combate à doença de Chagas, se torna muito difícil, pois o protozoário é encontrado em tatus... novamente retoma os motivos da doença não pelas condições de vida da população, mas nesse momento a culpa é da natureza, sempre desviando a atenção para causas secundárias.

\section{UM ESFORÇO DE INTERPRETAÇÃO}

O apagamento do político, do ideológico e do histórico é muito acentuado nesse material. É como se a linguagem da disciplina de ciências se irmanasse com a censura.

Conforme nos esclarece Orlandi (1995b) "a relação dito/não-dito pode ser contextualizada sócio-historicamente, em particular em relação ao "poder-dizer" ... é o não dito necessariamente excluído... O silêncio trabalha assim os limites das formações discursivas, determinando conseqüentemente os limites do dizer" (p. 76). 
Esse tipo de silenciamento encontrado nos módulos, ou a política do silêncio, cujo sentido nos remete à censura pode muito bem ser explicitado como uma produção do silêncio circunstanciada em relação à política.

Uma das dúvidas mais pertinentes dos professores dessa escola era se com esse material conseguiriam um ensino que ampliasse a visão de mundo dos alunos, uma visão mais crítica da realidade. O silêncio e o implícito encontrado nos módulos mudou de forma conforme a história, pois após nove anos, apesar do término do governo militar, o material ainda era o mesmo. Esse silêncio encontrado pelos professores os motivou a resistirem ao que não estava dito e que precisava ser explicitado. Nesse caso a política do silêncio interferiu nove anos após sua produção materializada nos módulos elaborados em 1978, dando origem a um trabalho de resistência dos professores em 1987.

Os professores angustiados perante a leitura de textos dessa natureza, cuja interpretação era de um conteúdo neutro, acabado, sem relações com os reais problemas da sociedade, pensaram formas de "auxiliar o aluno em suas próprias interpretações". Neste sentido resolveram colocar textos mais atuais nos módulos, refizeram provas com espaços para questões polêmicas onde os alunos pudessem se colocar (por exemplo, qual a relação entre a pobreza e a verminose?), e em alguns momentos instituíram aulas teórico-práticas para a discussão de conteúdos silenciados nos módulos, com eventuais observações ao microscópio, enfim deram enfoque a outros conteúdos.

As atuações dos professores certamente priorizaram determinados conteúdos tentando preencher o silêncio imposto pelo político, (esquecendo-se que os sentidos não são definitivos). Neste aspecto entra a questão do silêncio fundador (Orlandi, 1995b). Se o silêncio é constitutivo da linguagem e há sempre sentidos a dizer, conseqüentemente a falha e o possível estão no mesmo lugar e são funções do silêncio:

\footnotetext{
"É nessa perspectiva que consideramos a linguagem como categorização do silêncio, isto é, ela é a gregaridade, a possibilidade de segmentação, ou melhor, o recorte da significação em unidades discretas. Entretanto, uma vez recortado, o sentido permanece sempre a ser ainda dito." (p. 73)
}

Em outras palavras o silêncio revela a incompletude, a ponta de um iceberg... 
Nesse caso, em função do silêncio imposto pelos módulos, o esforço dos professores produziu outros deslocamentos de sentidos, pois ao abordarem conteúdos com enfoques sociais, muitas vezes pretendiam trocar um discurso que consideravam incorreto, por outro politicamente correto, esquecendo-se que os sentidos não estão colados às palavras. O discurso "panfletário" trazia em seu bojo outro discurso - o verdadeiro. Era como se quisessem trocar uma ideologia por outra, que em sua opinião seria a verdadeira, esquecendo-se das contradições que tecem as relações da organização do trabalho pedagógico na escola e das concepções individuais. Em conseqüência disso e como o discurso é o efeito de sentidos entre os interlocutores, muitas vezes os alunos dissimulavam o que realmente pensavam, concordando assim com a ideologia que o professor queria transmitir, deixando para ele a ilusão de uma filiação de sentidos. Um bom exemplo é o ensino da teoria da Evolução, onde normalmente os alunos adultos, cujas explicações são baseadas na religião, respondem corretamente aos professores sobre essa teoria, porém quando estão fora da escola explicam tudo sob a ótica da religião.

Nesse esforço voltado para as mudanças na escola, a visão era ingênua enquanto se acreditava numa concepção mecaniscista de língua, utilizada somente como instrumento de comunicação, buscando um sentido verdadeiro em ciências, fugindo das metáforas.

Mas os sentidos são em função da inscrição de formas capazes de jogo na história e a posição do aluno, enquanto sujeito ativo na interpretação produz diferentes sentidos. Conforme nos esclarece Orlandi "o espaço da interpretação, é o espaço do possível, da falha, do efeito metafórico, do equívoco, em suma: do trabalho da história e do significante, em outras palavras, do trabalho do sujeito." (1996, p. 22)

Apesar desses equívocos explicitados, em gestos de interpretação é possível ver as formas possíveis construídas por alunos e professores sobre o material. No caso do professor o que certamente existe por trás desse esforço é a sua própria interpretação do ensino e a busca de melhores condições de aprendizagem nessa escola. Ou seja, essa interpretação motivou intervenções que de certa forma contribuíram para um ensino melhor, dando aos alunos acesso a outros discursos que deveriam estar presentes no discurso científico da escola, por exemplo, os conteúdos com enfoques sociais. 
No entanto essa análise também é uma interpretação de um fato e expor esses equívocos esclarecendo o que não é visível é uma das funções da interpretação. Como diz Orlandi " o equívoco é o fato constitutivo do próprio sujeito transpassado pelo imaginário". Com essas leituras e nossas interpretações sobre Análise do Discurso nos filiamos aos sentidos e deslocamos os pensamentos. Assim sendo o passado evolui quando analisamos um fato dentro de um determinado espaço de tempo, num determinado contexto, pois daí surgem outras interpretações.

Nós estabelecemos nesse trabalho que, quando consideramos a leitura como um processo, é preciso levar em conta as outras possíveis interpretações, pois ela só acontece durante a interação entre o sujeito e o texto, dependendo das condições de produção dessa leitura: quem é esse sujeito, quais são suas histórias de leituras, qual o conhecimento que já possui, quais as expectativas naquele momento, em relação ao professor, aos colegas, ao texto, enfim consideramos uma série de variáveis que constituem esse sujeito.

Também ressaltamos que a leitura e a escrita no ensino de ciências, parecem ter uma tradição, estabelecida pela própria cultura escolar, de ser responsabilidade somente da área de ensino de Língua Portuguesa. Mesmo no campo da pesquisa em ensino de ciências, vimos que poucos são os trabalhos que têm se dedicado a estudar essas questões. Se o fazem, há quase sempre uma forte descontextualização sobre a vida da sala de aula ou da escola, priorizando apenas um avanço nas concepções científicas dos estudantes. Porém, esperamos que trabalhos dessa natureza possam auxiliar o repensar da leitura e da escrita, peças fundamentais no ensino de ciências, merecendo uma maior atenção. 


\section{Referências}

Almeida, Maria José.P.M. \& Souza, Suzani C. (1996) Possibilidades, Equívocos e Limites no trabalho do professor/pesquisador-Enfoque em ciências. Revista Investigações em Ensino de Ciências" - UFRGS http://w.w.w.if.ufrgs.br/public/ensino/N2/2indice.htm.

Apple, Michael W. (1982) Ideologia e Currículo. São Paulo, Ed. Brasiliense, 9-42 e 125-157.

(1985) Educação e Poder. Porto Alegre: Artes Médicas, 55-107

Authier, Jaqueline (1982) La mise en scène de la communication dans des discours de vulgarisation scientifique Langue Françoise no. 53 - p. 34-47.

Germano, J. W. (1982) Lendo e aprendendo - A campanha de pé no chão. São Paulo, Cortez ed.

Nagel, Tomas \& Richman, P. T.(1974).Ensino para competência: uma estratégia para eliminar o fracasso. Porto Alegre, Ed. Globo.

Orlandi, Eni. P. (1996) Interpretação: autoria, leitura e efeitos do trabalho simbólico. São Paulo, Ed. Vozes.

Orlandi, Eni P.( 1995a) O discurso da Educação Ambiental in Trajber, Raquel \& Manzochi, Lúcia Helena. Avaliando a Educação Ambiental no Brasil: Materiais Impressos, São Paulo Ed. Gaia 1996.

Orlandi, Eni P. (1995b) As formas do silêncio. Campinas: Ed. da Unicamp..

Orlandi, Eni P. (1993) Discurso e leitura. Campinas: Cortez.

Pecheux, Michel (1993) O Discurso. Campinas: Pontes. 
Pecheux, Michel (1990) Por uma análise automática do discurso. Campinas, Ed. da Unicamp.

Souza, Suzani C. (1995). Supletivo individualizado: possibilidades, equívocos e limites no ensino de ciências. Dissertação de mestrado, Unicamp.

Souza, Suzani C \& Almeida, Maria José (2001).Leituras na mediação escolar em aulas de ciências: A fotossíntese em textos originais de cientistas. Pro-posições, vol 12, n. 1[34], FE-Unicamp,

\section{ANEXO - Texto extraído do material didático de no. 06}

\section{DOENÇA DE CHAGAS}

A fim de destacarmos os principais problemas relacionados com a doença de Chagas, transcrevemos abaixo o texto extraído do livro "Saúde-Programa 1" de Paulo Maurício Silva e S. R. Fontinha Filho.

Leia o texto e responda as questões que são feitas a seguir.

\section{A TERRÍVEL DOENÇA DE CHAGAS}

Carlos Chagas foi um cientista brasileiro que, em 1907, descobriu como era transmitida a doença que passou a ter o seu nome.

A doença de Chagas é transmitida por um percevejo popularmente chamado barbeiro. Esse nome se deve ao fato de o percevejo quase sempre picar o rosto das pessoas para se alimentar de sangue durante a noite. Durante o dia, os barbeiros se escondem nas frestas das portas e das paredes ou na palha do telhado de casebres.

Quando o barbeiro pica uma pessoa durante a noite, deixa fezes depositadas sobre a pele. Essa fezes podem conter o protozoário denominado Trypanosoma cruzi, causador da doença de Chagas. Nesse caso a pessoa picada, ao se coçar, facilita a entrada do protozoário em sua corrente sangüínea, o qual se aloja em várias partes 
do corpo. Quando o protozoário atinge o coração da pessoa, a doença passa a ser muito perigosa.

O melhor meio de se evitar a doença de Chagas é combater o barbeiro que é seu transmissor. O combate é feito com um inseticida chamado BHC. Outra forma eficiente é a construção de casas, com paredes de tijolos e argamassa, portas sem frestas e cobertura de telhas.

O combate à doença de Chagas se torna difícil, pois o protozoário é encontrado em tatus, tamanduás, macacos, gambás e animais domésticos que transmitem 0 protozoário para o barbeiro.

Data de recebimento:30/01/2006

Data de aprovação:24/05/2006 